\title{
A synchronized strategy to minimize vehicle dispatching time: a real example of steel industry
}

\author{
K. R. Zuting $\cdot$ P. Mohapatra $\cdot$ Y. Daultani • \\ M. K. Tiwari
}

Received: 2 December 2013/Accepted: 24 May 2014/Published online: 17 June 2014

(c) Shanghai University and Springer-Verlag Berlin Heidelberg 2014

\begin{abstract}
Time compression in supply chains is a crucial aspect involved in the integration of warehousing and transport operations in the manufacturing industries. Supply chain flows could be interrupted due to many sources of delays that lead to additional time in dispatching process and reduction in customer service level. The problem considered in this paper consists of long waiting times of loading vehicles inside the plant. This work presents a simulation-based study to minimize vehicle dispatching time in a steel wire plant. Value stream map is developed to present a system perspective of processes involved in the overall supply chain. Process activity mapping is completed to provide a step by step analysis of activities involved in the vehicle dispatch process. A simulation model is developed for the system and a new model is proposed to improve the delivery performance by minimizing vehicles' waiting time.
\end{abstract}

Keywords Vehicle dispatch process - Discrete event simulation · Lean thinking · Value stream mapping · Process activity mapping

\section{Introduction}

Process time compression is an important contemporary issue in supply chains. A vast portion of process time

\footnotetext{
K. R. Zuting · P. Mohapatra $\cdot$ M. K. Tiwari $(\bowtie)$

Department of Industrial Engineering, Indian Institute

of Technology, Kharagpur 721302, India

e-mail: mkt09@hotmail.com

Y. Daultani

Operations Management Group, Indian Institute of Management,

Lucknow 226013, India
}

reduction is achieved by appropriate vehicle dispatching policies. In context of manufacturing sector, vehicle dispatching integrates the warehousing and transport operations and involves three sub-processes namely: entrying plant of the vehicle, material loading procedures under capacity constraints, and finally departure from the premise. Any kind of delay in these sub-processes increases the dispatching time and hence results in poor customer service level and increasing of warehouse/transportation costs [1].

A case demonstrated in this paper is based on the vehicle dispatch operations of a steel wire manufacturer based in India. Products are either dispatched from the plant to the stockyard or directly to customers. Due to the negative correlation between profit and inefficient vehicle dispatching policies, primary focus of both the manufacturers and customers lie on the compression of waiting time. Figure 1 depicts the plant's vehicle dispatch process.

In this paper, we focus specifically on the vehicles arriving for the loading of low relaxation pre-stressed concrete (LRPC) coils. In our case, vehicle dispatch time for this product is the highest among all products with a value of about $265 \mathrm{~min}$. We aim to compress this dispatch time nearer to the benchmark of WUJI-China (steel processing plant in China), in which dispatches LRPC coils within just $20 \mathrm{~min}$. To achieve such a drastic compression, a simulation-based methodology has been devised to ensure the desired resource throughput.

The remaining sections of the paper are organized as follows. Section 2 provides the main literature review about the different works and models developed for the vehicle dispatch process design and control. Section 3 presents the case study developed in this work. The research methodology is described and developed in Section 4. Conclusions and results of the simulation model are discussed in Section 5. 


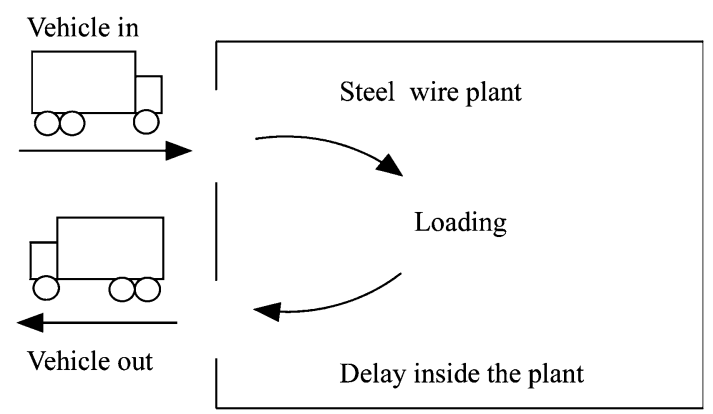

Fig. 1 A simplified view of the vehicle dispatch process

\section{Literature survey}

Over the past half a century, lean thinking is widely used in manufacturing settings to create and deliver value for customers. According to lean management principles, all operations should be rationalized, which means the elimination of waste in any form, anytime, anywhere. To achieve this, activities are categorized as value-adding and non-value adding (or wastes). Lead time reduction is achieved by taking the non-value adding activities out of the process. A lean supply chain is one, which produces just what is needed, when it is needed, and where it is needed [2]. The lean thinking in supply chain is to produce more or do more with fewer resources, while satisfying the end customer. It requires to focus on each product and its value stream. To achieve these objectives, organizations must be prepared to identify the real value-adding activities. The main idea behind lean is not simply about eliminating wastes, but rather eliminating waste and enhancing value simultaneously.

There are very few research works linking dispatch processes to storage and transportation operations. Manson et al. [3] presented an integrated system for warehousing and transportation to improve the visibility in supply chains. They examined the benefits of coupling inventory control to dispatching and sequencing techniques and rules through a simulation study. Potter and Lalwani [4] discussed time delay by a case study on the dispatch process in the steel industry. They proposed a methodology that includes value stream mapping (VSM) and the aim of VSM which is to provide a single sheet overview of the processes involved in whole supply chain. Thus, VSM helps to know how the material flows vary towards the dispatch bay location. Process activity mapping (PAM) gives the average time and resources requirement for each step in that process. Detailed insights about the behavior of the processes and associated areas for improvement can be identified using data analysis tools and techniques. We aim to reduce the vehicle dispatching time by identifying the non-value adding activities from the process. For this purpose, we have used the tools and techniques of lean concept, value stream mapping and process activity mapping followed by discrete event simulation modelling.

Discrete event simulation (DES) model is used to test the potential improvements and associated benefits in a dynamic environment. Potter et al. [1] discussed a problem that includes inefficiencies in the dispatch bay performance which is a critical interface between organization's internal processes and transport operations. The inefficiencies in this area are that delays lead to additional costs of warehouse and transportation and also to poor customer service. These delays also affect the time a vehicle spends to move from the industry. Aiming at reducing the time taken for whole dispatch process for both information and physical flows and to eliminate weekend working, which incurs additional cost for the companies, Ref. [1] proposed a DES model to test the benefits of integrating warehouse and transport management system. This work suggested that a reduction of $26 \%$ in the vehicle dispatch time could be achieved by removing wastes from the process, with a further $20 \%$ reduction which can be achieved by investing in technological improvements. Juntunen and Juga [5] showed that bullwhip effect can be controlled by managing the transportation capacity in supply chains. They developed a model to intend to prove that transportation operations and dispatch events could play a role in reducing the effects of demand amplification and inventory variations. Besides, different types of analytical models have been used. Zhao et al. [6] developed a Markov decision model to formulate both ordering and delivery problems. To foster the qualitative aspects of the layout solving methods and tools, artificial intelligence techniques such as neural networks [7] and expert systems [8] have been applied. However, incorporating randomness in the model limits the use of these analytical models towards the use of DES.

\section{The case study}

The steel wire plant under study is a major player in the market, serving the needs of its customers globally. The plant manufactures a wide variety of wires that are required in various industries like automotive, infrastructure, power and general engineering. Products are supplied to the warehouses at different locations as well as directly to the customers. The problem of long sojourn of loading vehicles inside the plant is faced at various dispatch locations in the plant. At first, this work mainly concentrates on single location and single product type. The developed methodology can be applied to other locations and products as well.

The plant operates 6 days a week, with daily dispatches occurring between 9:00 a.m. to 9:00 p.m. However, long dispatch times create backlogs, requiring overtime on 


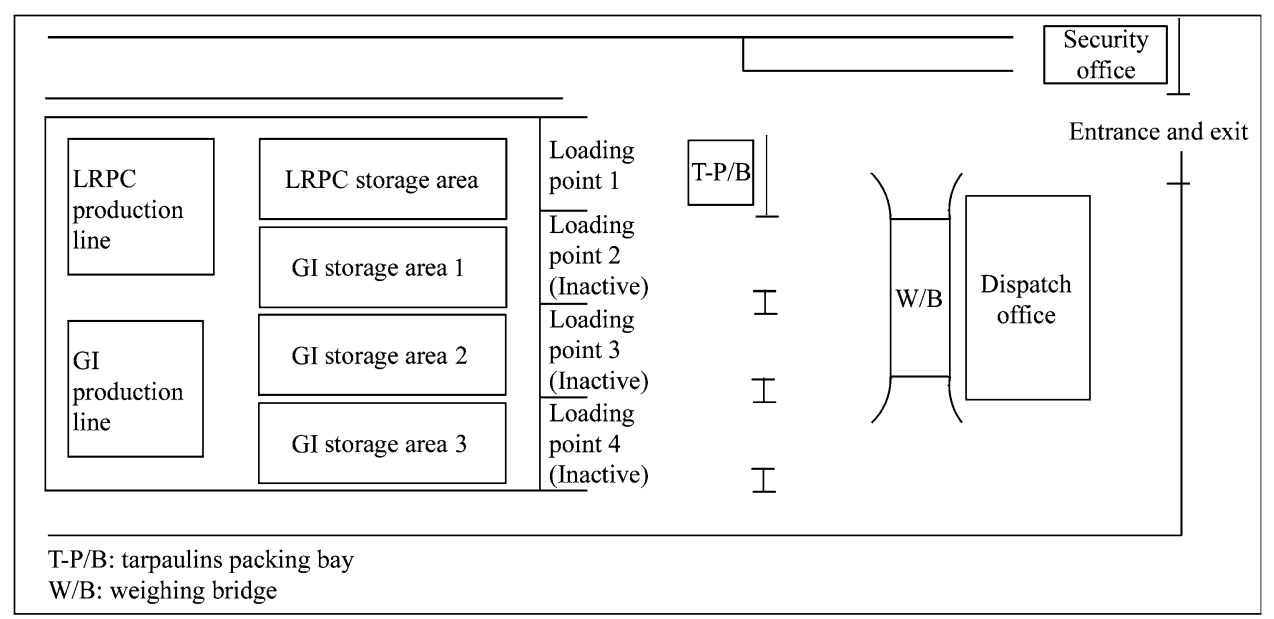

Fig. 2 Dispatch area layout

Sundays. At present, vehicle dispatching times are tracked using an enterprise resource planning (specifically, SAP) system. Marketing department actors generate daily delivery orders using SAP. This information is communicated to plant transport supervisors as well as to the third party logistics (3PL) providers to arrange required vehicles within $24 \mathrm{~h}$. As vehicle arrives at the plant, it is sent to the weighing bridge for the tare weight measurement. Tare weight is entered to SAP and vehicle is sent to the loading location inside the plant. Gross weight is measured after vehicle loading and is entered to SAP along with the invoice completion time. The duration between tare weight measurement and invoice generation gives the time of vehicle dispatch process for that particular vehicle. As the exact entry and exit times of vehicle are not entered to SAP, supervisors are unable to track the exact time spent by a vehicle inside the plant. Layout of the dispatch area in steel wire plant is shown in Fig. 2.

Vehicle operator reports the security office and obtains security clearance. It is then sent to the weighing bridge for the tare weight measurement. Next, it is moved for the loading at different loading points/locations as required. It has to wait in a queue, if the loading point is already occupied. Once the materials/products are loaded, vehicle is moved to the weighing bridge again. After gross weight measurement, vehicle is sent to the tarpaulins packing bay (T-P/B). After covering the material with tarpaulins, the vehicle moves out of the plant.

\section{Research methodologies}

We identified main methodologies that could be used for the system analysis and to improve its performance by eliminating wastes from the system through an extensive literature review. The methodology proposed for the case study is based on the decomposition of the activities and development of a DES model to capture the random features of the events. It also provides suitable suggestions for plant's performance improvement. Figure 3 shows the adopted methodological approach.

Value stream map (VSM) is developed in the first stage. VSM provides a single sheet overview of the processes involved across the supply chain [9]. It is quite necessary to analyze the dispatch process, as it is the interface between warehousing and transport system and its performance may be affected by the downstream or upstream processes.

Process activity map (PAM) is developed in the second stage. PAM provides a step by step decomposition of the given process [10]. This gives the average time taken by all the activities involved in any process along with the

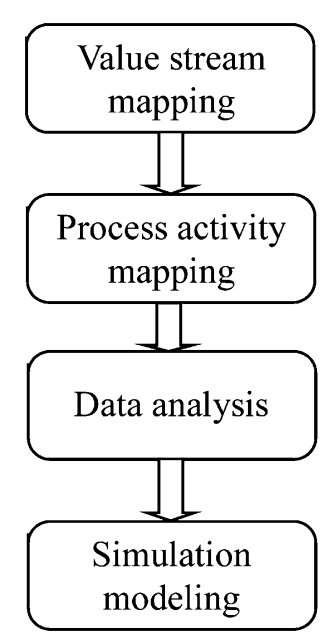

Fig. 3 Methodological approach 


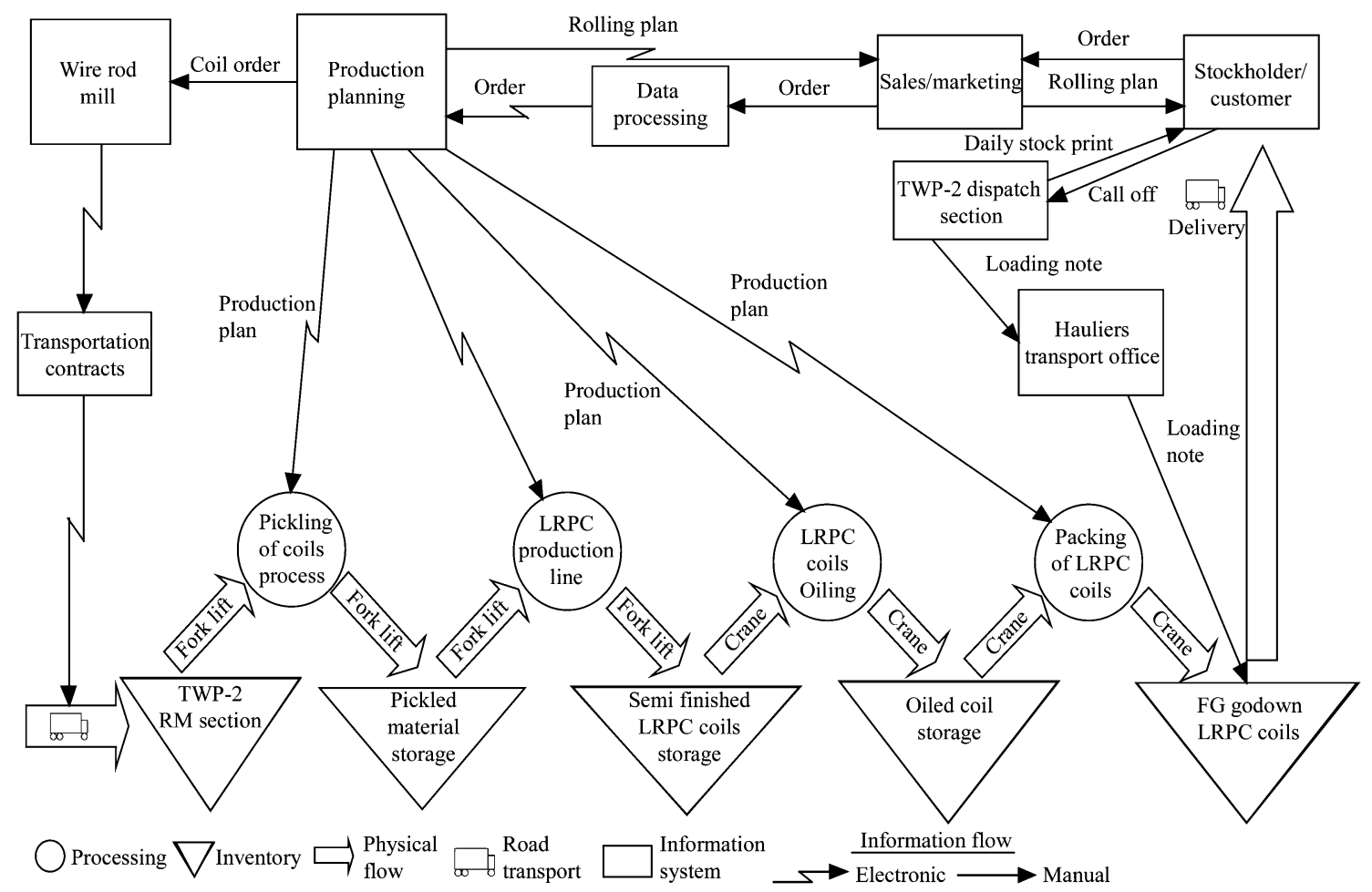

Fig. 4 Value stream map for LRPC product of steel wire plant

resource requirements at each step. These activities are then classified as operation, transport, inspection and storage or delay. Since our aim is to minimize the delay and maximize the operation time with the help of PAM, the contributions of activities under those categories are then identified. As a consequence, the process performance improvement is made possible by eliminating the wastes or non-value added activities (such as delays).

Statistical analysis of operations related data is carried out in the third stage. Data analysis gives detailed insights about the behavior of the processes, and also helps finding out the areas for improvement which cannot be identified by process activity mapping alone. The analysis reveals the information about where exactly the process is delayed. The purpose of PAM and data analysis is to provide improvement suggestions in a short period of time.

At the final stage, we develop a simulation model to test potential improvement and to measure the benefits observed in changing state of the system. PAM focuses only on the average values, and does not capture the response to the changing behavior or the interaction between call-offs as they pass through the process. This is very important when the activity time is extended due to queuing in the shared resources. One of the advantages of PAM is that it helps to group the individual steps in activities. This makes the model development easier and reduces the data requirement.

\subsection{Value stream mapping}

This stage involves developing the VSM. The aim of using VSM is to provide a single sheet overview of processes involved in the whole supply chain. VSM for LRPC product of steel wire plant is shown in Fig. 4.

It particularly shows that the product moves to dispatch bay on the site. Plant receives orders from the customers and controls the buffer stocks. Based on the orders received, production plan is prepared for each type of product. Production process involves rolling of seven different wires to be stranded together to form a single wire. After manufacturing operations, quantity is updated in SAP. This information is passed to the steel processor, and is known as call off. Deliveries are then made by road using third-party haulers. Delivery order prepared by marketing the department is viewed by the dispatch section. This information is used to call off the transporters to deliver the material as required. Once the vehicle arrives to the plant for loading, this dispatch process consists of several standard activities.

\subsection{Process activity mapping}

Common name of PAM is process analysis which consists of following five major steps: (i) study of processes flows in the system; (ii) identification of waste processes in the 


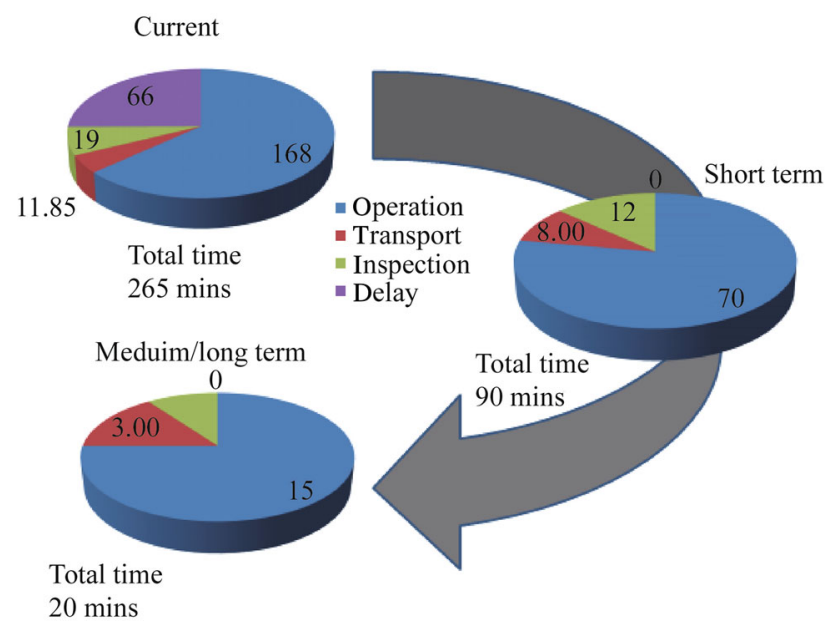

Fig. 5 PAM for vehicle dispatch process

system; (iii) rearranging the processes in order to find out the efficient sequence; (iv) finding out a better flow pattern, modifying the flow layout; and (v) identifying and removing unnecessary tasks in the system.

PAM involves a step-by-step analysis of the activities making up the process. Information about the average time taken and resource requirements is noted for each step. The aim is to minimize the delay time and to maximize the operation time. PAM helps to classify all the activities involved in vehicle dispatch process in four major categories, i.e. operation, transportation, inspection and delay. Times for the whole process and for each category of activity are calculated. Figure 5 shows PAM for the vehicle dispatch process.

It highlights the opportunity to reduce time in whole process. It also identifies the resources requirement for each category of activity. Three scenarios are analysed namely: current situation, short term situation and medium/ long term situation. Current situation depicts the average process time of vehicle dispatch process that is obtained from the data collected. Vehicle dispatch process consists of 14 activities. These activities are classified in four categories: operation, inspection, transportation and storage/ delay. Contributions of these activities in the categories mentioned above are shown in the current situation. Short term situation is obtained using the takt time concept of lean thinking. Takt time is one of the key lean principles. It is defined as the pace of production with respect to the customer demand. Takt time sets the "rhythm" of the organization in synch with customer demand. As one of the three elements of just-in-time, one-piece flow and production pull, takt time balances the workload of various resources and is used to identify bottlenecks. We have used this concept to find out the rate of vehicle dispatch process with respect to the number of delivery orders received per day.

Takt time calculations for a vehicle dispatch process are as follows:

$T=\frac{T_{\mathrm{a}}}{T_{\mathrm{d}}}$,

where $T$ is takt time, e.g. (minutes of work/unit produced), $T_{\mathrm{a}}$ actual time available to work, e.g. (minutes of work/ day), and $T_{\mathrm{d}}$ time demand (customer demand), e.g. (units required per day).

Average daily dispatch of LRPC coils: $72 \mathrm{t}$;

Weight of LRPC coil: $3.0 \mathrm{t}-3.5 \mathrm{t}$;

Average number of coils dispatched daily: $72 / 3=24$;

No. of coils loaded in one vehicle: 4 to 5 ;

Dispatch section work timings: 9:00 am to 9:00 pm;

Total available time: $12 \mathrm{~h}=720 \mathrm{~min}$;

Idle time break up: breakfast $=20 \mathrm{~min}$; lunch break $=$ $45 \mathrm{~min}$; shift changing $=50 \mathrm{~min} ;$ snacks $=20 \mathrm{~min}$; dinner $=45 \mathrm{~min}$.

Total idle time $=20+45+50+20+45=180 \mathrm{~min}$.

Actual time available to work

$T_{\mathrm{a}}=$ total available time - idle time $=720-180=540 \mathrm{~min}$.

Vehicle capacity: $10 \mathrm{t}-16 \mathrm{t}$.

Assuming number of coils loaded in each vehicle: 5 .

Number of vehicles dispatched daily

$\begin{aligned} T_{\mathrm{d}} & =\frac{\text { Average number of coils dispatched daily }}{\text { Number of coils loaded in one vehicle }}=\frac{24}{4} \\ & =6 \text {. }\end{aligned}$

Takt time for dispatch process

$$
\begin{aligned}
T & =\frac{\text { Actual working time available } T_{\mathrm{a}}}{\text { Number of vehicle dispatched daily } T_{\mathrm{d}}}=\frac{540}{6} \\
& =90 .
\end{aligned}
$$

Thus, takt time for every vehicle dispatch process is $90 \mathrm{~min}$.

Long term situation to be achieved from this work is based on benchmark of Wuji, China, as mentioned in Section 1. This requires application of the improvement strategy continuously for the vehicle dispatch process. From Fig. 5, it is clear that there are many differences in these three scenarios. This is due to the difference in the non-value added activities in the process. PAM depicts that there are many variations in these time, which requires further analysis of the process. 
Table 1 Data collection form of vehicle dispatch process for LRPC dispatch

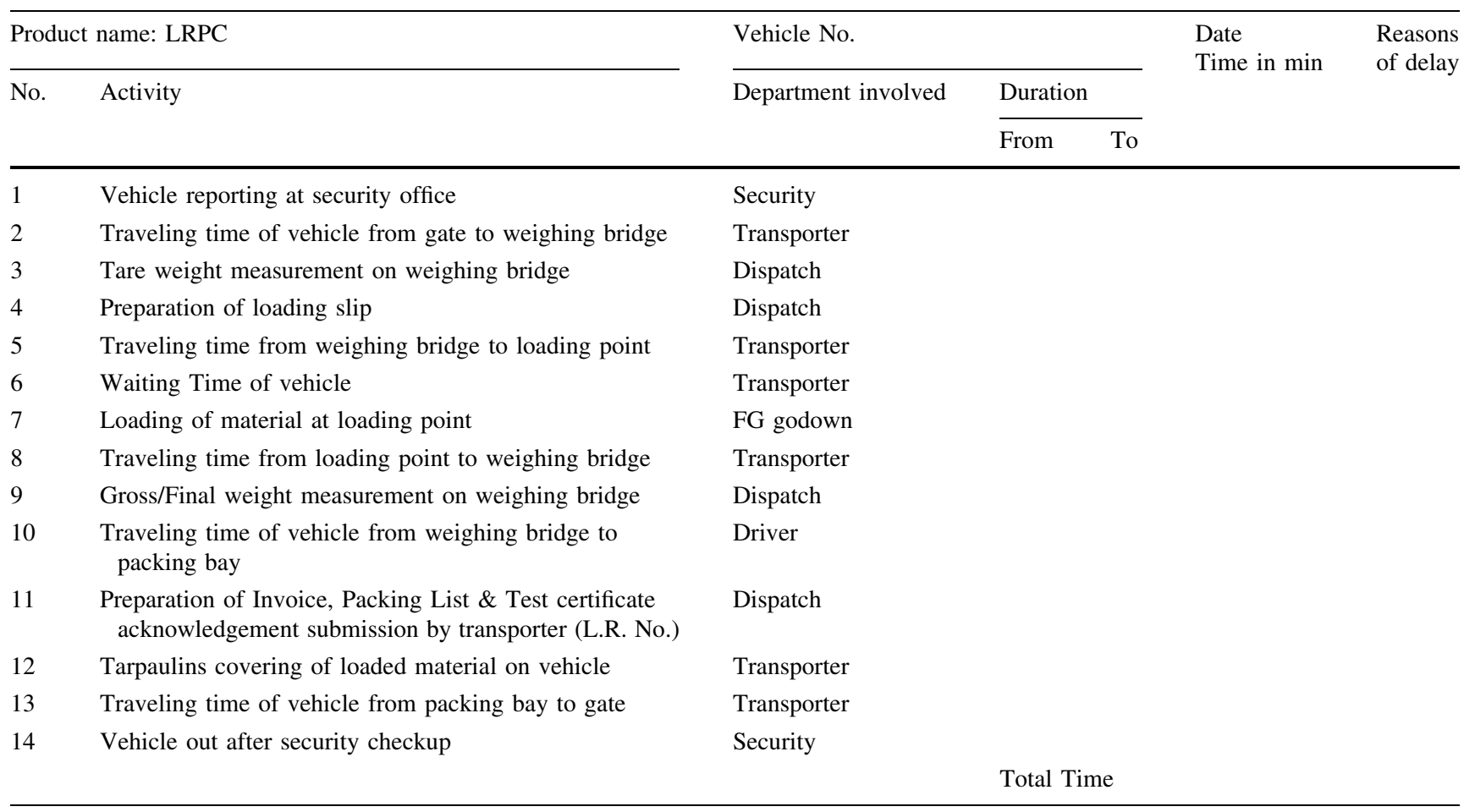

\subsection{Data analysis}

In a vehicle dispatch process, it is essential to find the time for activity and corresponding reasons of delay. It is also necessary to track the movement of a vehicle as it has to visit many locations inside a plant to get loaded. The new format prepared to collect the data is shown in Table 1.

It includes all activities involved in a vehicle dispatch process. Departments involved in those activities are also mentioned. The column "Reasons of delay" will help to find the major reasons for incurring delays in the process for a particular activity. Data are collected for 65 vehicle dispatches. Data are analyzed in various ways. Firstly, descriptive statistics is used to find the average time for each activity and for the complete process. Average time for vehicle dispatch process is $265 \mathrm{~min}$. Most of the vehicles are dispatched in less than $5 \mathrm{~h}$. The waiting time in queue for each activity involved in vehicle dispatch process is of major concern. It is possible to get a clear picture of vehicle dispatch process from data analysis. Furthermore, percentage contribution of each activity to the whole process is calculated using Pareto analysis to find major causes of delay in vehicle dispatch process. Pareto chart, as shown in Fig. 6, is used to separate the "vital few from trivial many".

It states that 80 percent of the problems arise due to 20 percent of causes. Pareto charts can be used to identify the

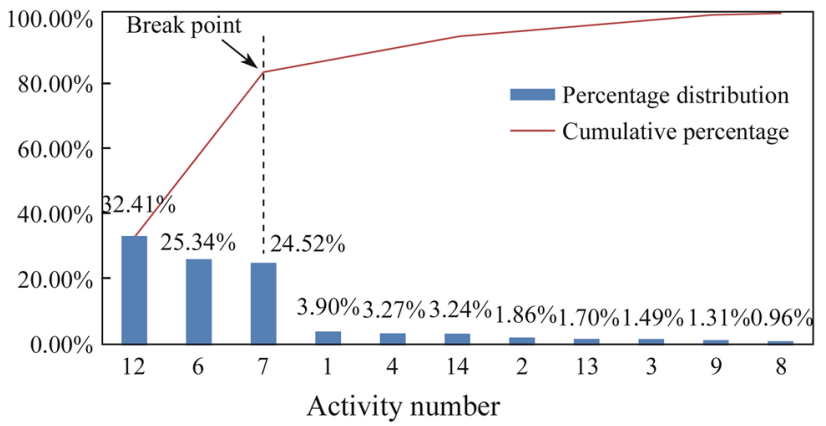

Fig. 6 Pareto analysis of activities involved in vehicle dispatch process

factors that have the greatest cumulative effect on the system, and thus screen out the less significant factors in an analysis. Ideally this allows the users to focus on a few most important factors in the process. By Pareto analysis, it is clear that activities 12,6 and 7 are the main causes to make delay (see Table 1). Table 2 shows the major time consuming activities along with their average time, percentage distribution and reasons of delay for those activities.

A fish bone diagram, as shown in Fig. 7, is then developed for the vehicle dispatch process and is used to identify potential factors affecting the process. Causes are grouped in major categories to find out the sources of variations. 
Table 2 Major time consuming activities

\begin{tabular}{lllll}
\hline No. Activity & $\begin{array}{c}\text { Average time } \\
\text { in minutes }\end{array}$ & $\begin{array}{l}\text { Percentage } \\
\text { distribution/ } \\
\%\end{array}$ & Reasons for delay \\
\hline 12 & $\begin{array}{c}\text { Tarpaulins covering of loaded } \\
\text { material on vehicle } \\
\text { Waiting time of vehicle }\end{array}$ & 85 & 32.41 & Low man power/wet tarpaulin covers/single packing bay \\
7 & 66 & 25.34 & $\begin{array}{c}\text { Often breakdown of material handling devices/vehicle in } \\
\text { queue/vehicle arrival rate/bad condition of vehicles } \\
\text { Improper material stacking/mixed stacking/material sorting } \\
\text { problem/breakdown of material handling devices/unavailability } \\
\text { of forklift/improper packing/wrong labeling }\end{array}$ \\
\hline
\end{tabular}

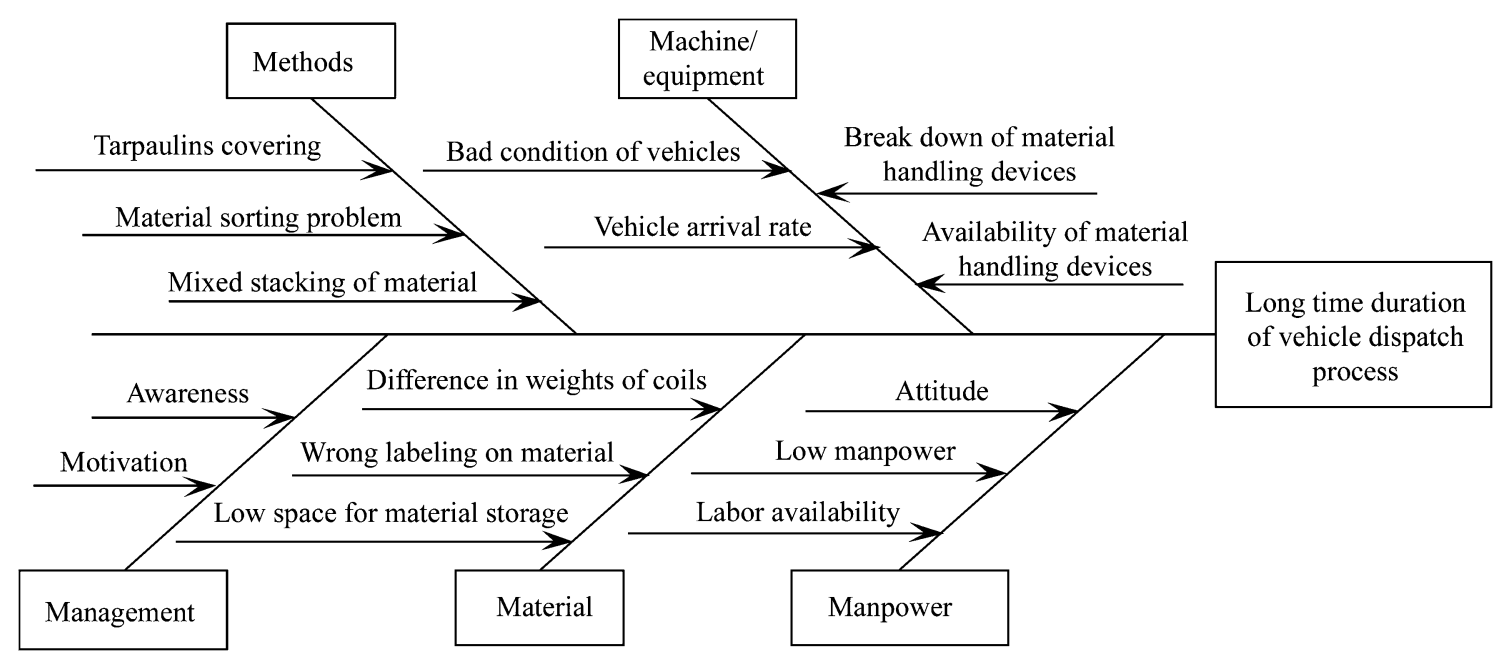

Fig. 7 Fish bone diagram for vehicle dispatch process

\section{Simulation modeling}

Final stage involves simulation modeling. Simulation helps to analyze the current system performance and to evaluate possible benefits from possible improvement strategies. Simulation has become an important and required aspect of corporating programs such as lean manufacturing, six sigma and customer relationship management. Simulation allows what-if analysis and quantitatively evaluates the benefits before implementation. Indeed, it helps to compare the operational alternatives without disturbing the real system and allows time compression so that time line decisions can be made [11]. Four types of simulation models can be used for supply chain modeling, namelyspreadsheet simulation, system dynamics simulation, DES and business game simulation [12]. Common applications of spreadsheet simulation and system dynamics simulation are production control and explanation of bullwhip effect, respectively [13]. Business game simulations are widely used in developing and educating supply chain practitioners [14]. DES is one of the most important simulation methods. It is based on an event or activity [15] and allows integration of stochastic and dynamic activity behaviors [16]. Vehicle dispatch process under study consists of different types of activities in a sequence, and thus, we use DES for our purpose.

ARENA software package is used for development of simulation models. This simulation software consists of the predefined modules (e.g., arrive, process, decision, delay, etc.). ARENA helps to visualize operations with dynamic animation graphics. This simulation software is widely used in the applications of manufacturing, logistics and supply chain management, distribution, warehousing and service systems. It consists of wide variety of modules that can be used to model manufacturing operations and queuing networks. We use it to simulate vehicle dispatch process as it consists of different types of modules to model queuing system and transport processes inside the plant as mentioned by Kelton et al. [17].

The first step in developing the simulation model is to identify the entities and the main performance measure in the vehicle dispatch process. In this case study, the vehicle arriving inside the plant against the delivery order of LRPC products is considered as an entity. Therefore, the time 


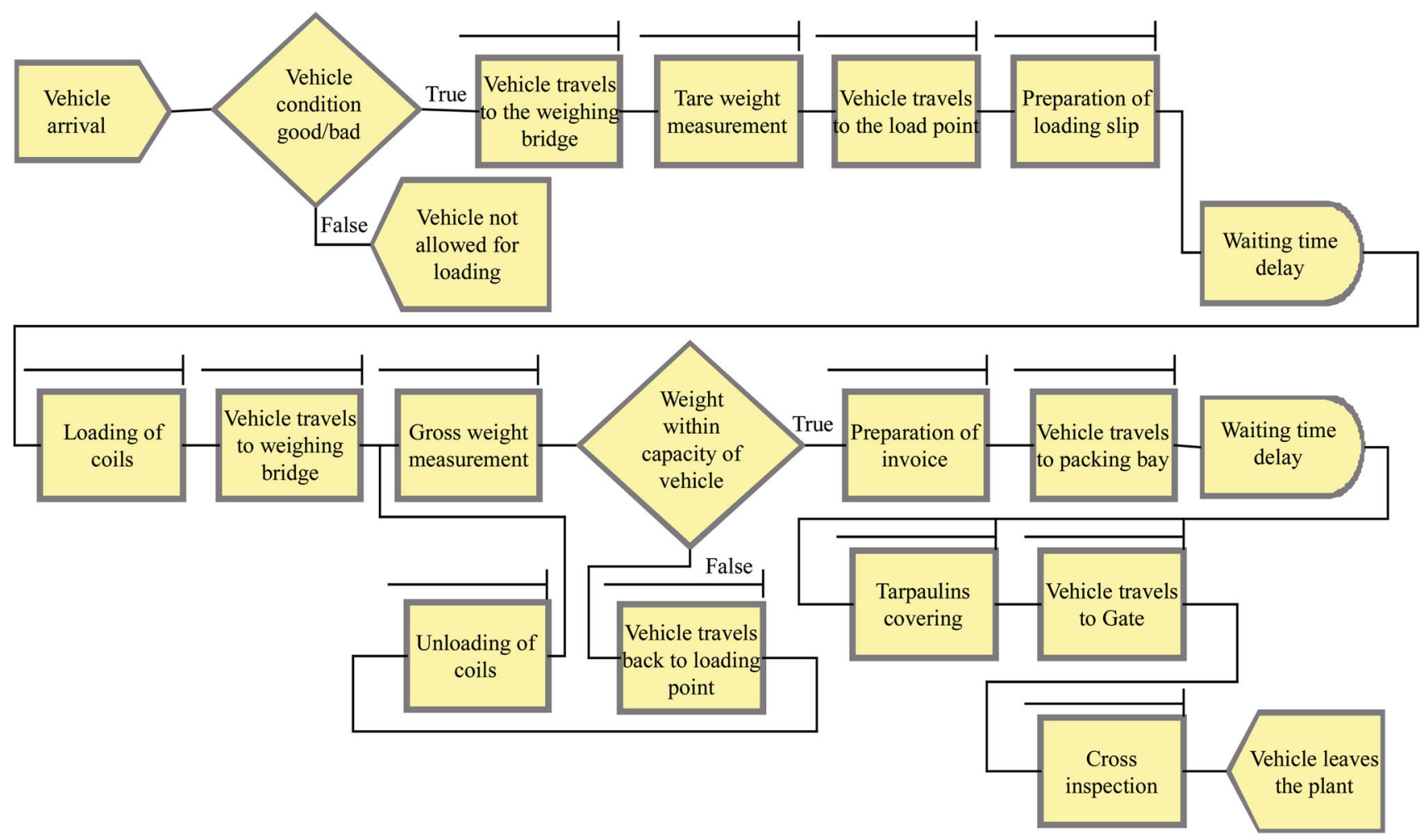

Fig. 8 Simulation model of existing system

taken for each entity (vehicle) to pass through the entire system (plant) is considered as the performance measure. Existing system is modeled using ARENA to identify current system performance. PAM depicts the overall view of vehicle dispatch process as discussed in Section 4.2. It provides the logical sequence of all activities involved in vehicle dispatch process along with the time and the resources requirement for each activity. Required dataset is the same as discussed in data analysis section. Using the collected data, it was possible to calculate the duration of various activities. Duration of each activity is noted in minutes and ARENA's input analyzer function is used to generate the distribution while minimizing the squared errors in data. After creating a model of existing vehicle dispatch process, the number of replications and the replication length have to be decided. Generally the replication length is decided based on the number of entities that pass through the system or the run time of model. Data were collected for 65 vehicles for particular period. Initially, the model was run using the actual data for arrival rates of vehicles, while using input analyzer to generate empirical distribution form the observed data. Figure 8 shows the simulation model for existing system.

Model starts from arrival of the vehicle in the system. The "create module" generates the entity (vehicle in our case) for system. As the vehicle arrives in the system, the "decision module" helps to take the decision for allowing the vehicle to enter inside the plant based on the vehicle's condition. Once the vehicle enters inside the plant it travels to the weighing bridge, as presented by the "process module". Likewise the process module is used to represent various activities involved in the vehicle dispatch process. Queue waiting time is represented by "delays module". At the end of model, entity (vehicle) is disposed via "dispose module". The dispose module is intended as the ending point for each entity in the simulation model. Proposed simulation model is of deterministic nature, as the relations among various states and activities are known and defined.

\subsection{Model validation}

One of the important steps in simulation is model verification and validation [18]. Verification is the process of analyzing the behavior of the model and its logic with respect to the desired level of abstraction. Data validation process consists of determining the appropriate statistical comparison of means test to execute. For example, if both system and model data sets follow normal distribution, we need to establish their similarity statistically, using hypothesis testing. Here, we have performed $t$-test statistics for model validation. The independent $t$-test is utilized when the datasets follow the normal distribution and have 
similar variance. This test determines whether there is any significant difference between simulation model and the real system at a given level of significance or not. In order to perform this test, we calculate the mean and sample standard deviation of both the data sets and the simulation model.

Assuming following notations:

null hypothesis $H_{0}: \mu=\mu_{0}$,

alternate hypothesis $H_{1}: \mu \neq \mu_{0}$,

where $\mu_{0}$ is the mean of the complete vehicle dispatch process time for LRPC products from observed data, and $\mu$ is the mean of the complete vehicle dispatch process time for LRPC products obtained from the simulation model.

\section{Calculations:}

mean from the observed data $\mu_{0}=265 \mathrm{~min}$, mean from the simulation data $\mu=263.82 \mathrm{~min}$, sample standard deviation $S=30.55 \mathrm{~min}$, number of data points $n=65$,

critical $t$ value at $95 \%$ confidence level and 64 degrees of freedom (from $t$ tables), $t_{(0.025,64)}=1.998$.

Thus, $t_{0}$ can be calculated as

$t_{0}=\frac{\mu-\mu_{0}}{S / \sqrt{n}}=\frac{263.85-265}{30.55 / \sqrt{65}}=0.322$.

Clearly, $t_{(0.025,64)}>t_{0}$. As the calculated value of $t_{0}$ is less than the critical value, null hypothesis cannot be rejected. It shows that the simulation model and the real system behave in the same manner.

After verification and validation, the simulation model is run for $12 \mathrm{~h}$ which corresponds to opening hours of the dispatch section. Results are interpreted in terms of waiting time, resource utilization and throughput time of the existing system. These results are presented in Table 3.

For the existing system, 5 vehicles can be dispatched per day. Utilization of different types of resources: manpower in dispatch section $\left(R_{1}\right)$, crane operator $\left(R_{2}\right)$, overhead crane $\left(R_{3}\right)$ and manpower for tarpaulins covering $\left(R_{4}\right)$ are shown in Fig. 9.

Waiting time in existing system is large due to various delays like breakdown of overhead crane and others (see Table 2). Effective resource utilization is low as resources are idle most of the time.

\subsection{Proposed simulation model}

A new simulation model is developed by including some improvements in the existing system with specified time line. A standardized work plan is established for the overall process based on various activity times, which results in the major process improvements. This could be implemented
Table 3 Simulation results of the existing system

\begin{tabular}{ll}
\hline Description & Numerical value \\
\hline Average value added time/min & 112.62 \\
Average non value added time/min & 56.36 \\
Average waiting time/min & 94.83 \\
Total average time in the system/min & 263.82 \\
Average number of vehicles dispatched per day & 5 \\
\hline
\end{tabular}

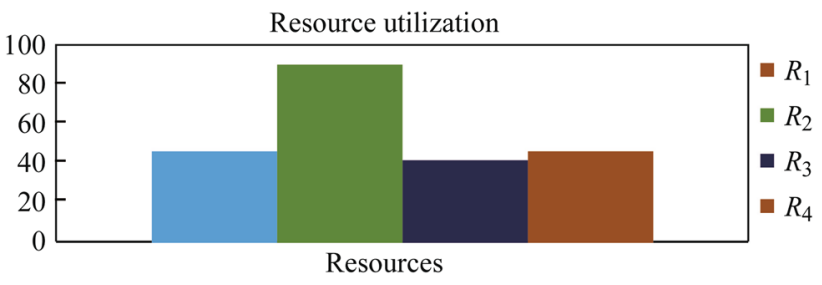

Fig. 9 Resource utilization as per the existing system

within the case study company to improve the performance of vehicle dispatch process. Main process improvements proposed in the vehicle dispatch process are: (i) material should be sorted near loading point before vehicle's arrival; (ii) work-force balancing involved in tarpaulins covering; (iii) material quantity should be updated in SAP correctly by production and quality department.

We note that process improvement is our main objective based on the problem detection in the vehicle dispatching process like resource misallocation or wrong ordering process. Along with the above process improvements, we also control the below mentioned environmental conditions: (i) material handling equipment should always be available in good conditions; (ii) labor availability during shift changing time.

A new model is proposed by incorporating the above described changes in the existing system. Figure 10 shows the simulation model of the proposed system for vehicle dispatch process.

A vehicle has to visit six locations to complete the dispatch process now. At each location, a particular process is carried out and the task should be finished within the specified time. In this model, all non-value adding activities (wastes) are eliminated in order to improve the performance of the system. The model is then run for $12 \mathrm{~h}$ and 100 replications. Results obtained from the proposed system are shown in Table 4.

By the proposed system, 8 vehicles can be dispatched per day. The results indicated that performance of the vehicle dispatch process can be improved under the suggested improvement strategy. Resource utilization as per the proposed system is shown in Fig. 11. Resources can be 

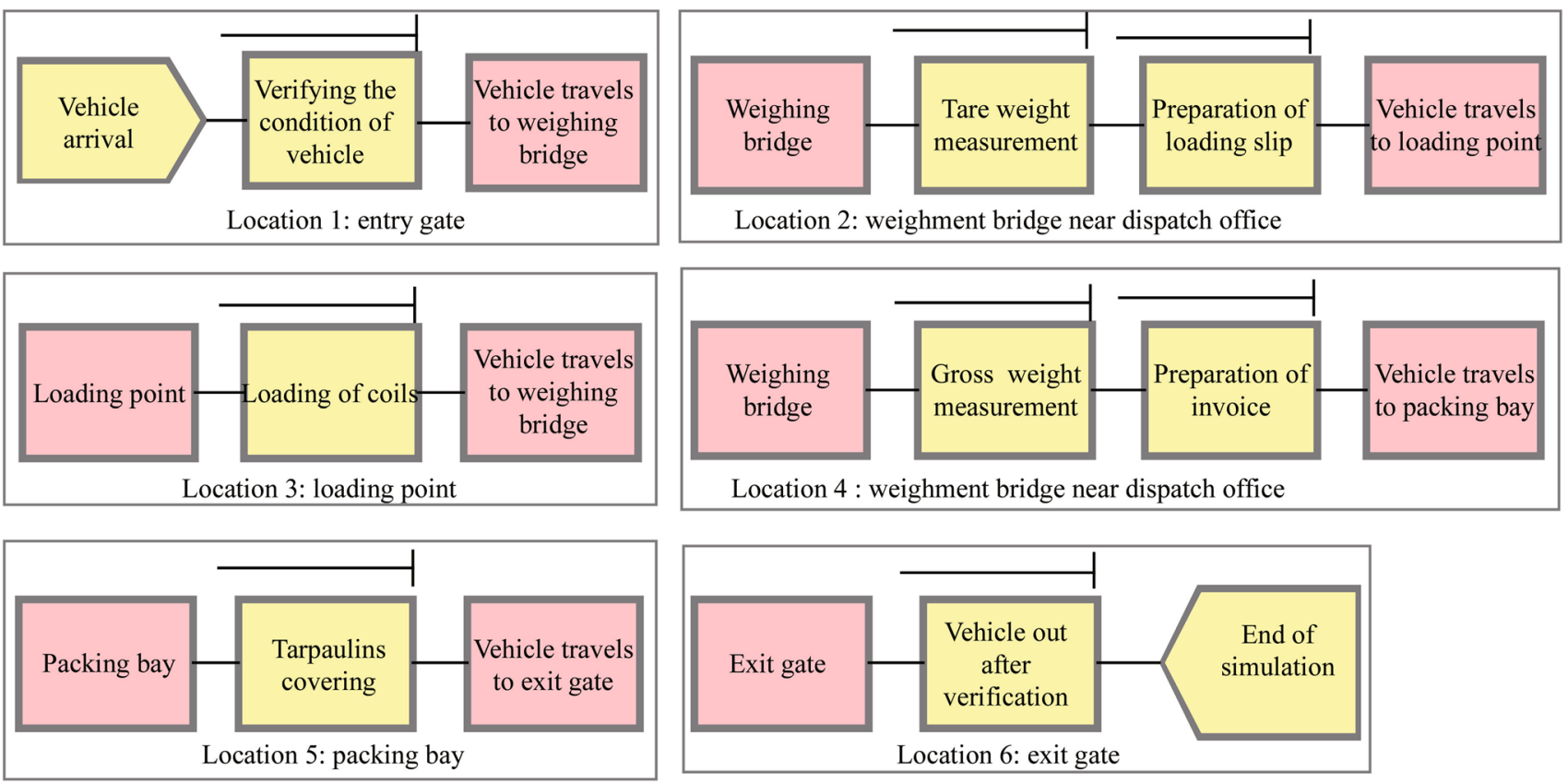

Fig. 10 Simulation model of proposed system

Table 4 Simulation results of the proposed system

\begin{tabular}{ll}
\hline Description & Time/min \\
\hline Average value added time & 25 \\
Average waiting time & 65.21 \\
Total average time in the system & 95.21 \\
\hline
\end{tabular}

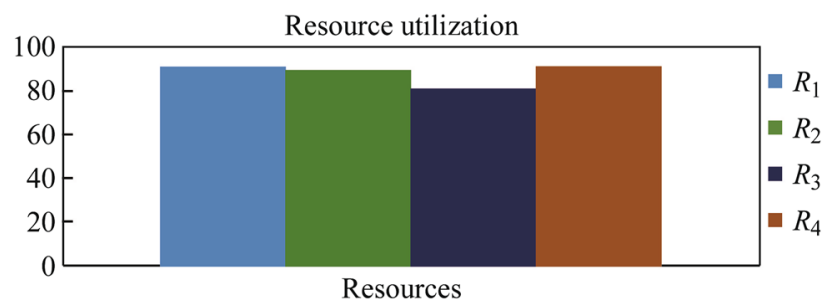

Fig. 11 Resource utilization as per the proposed system

utilized optimally by achieving standard conditions at each stage in the process. This represents the fact that, with some processes now being faster, the overall pace of the system changes as a result.

\section{Conclusions}

This work presents a synchronized strategy to minimize vehicle dispatching time based on the real case of a steel manufacturer. The importance of the vehicle dispatch process in achieving smooth product flows in supply chains has been identified and highlighted. Developed methodology combines several lean tools like value stream mapping and process activity mapping followed by discrete simulation modeling. Data analysis is performed to understand the behavior of the system. Proposed methodology aims to facilitate physical and information flow improvements in this area.

Results show that significant time compression can be achieved for the vehicle dispatch process, by removing several process wastes according to the lean thinking. Comparisons of the existing and proposed system show that the efficiency of vehicle dispatch process could be increased by $30 \%$. Actual process time could be reduced by $77.80 \%$. Total time of the vehicle dispatch process could also be reduced by $63.91 \%$ by removing several process wastes and by applying standardized work at each stage. As a result of our approach, the number of vehicles dispatched per day increased from 5 to 8 , and sales per day increased from $72 \mathrm{t}$ to $120 \mathrm{t}$. Waste activities include mixed material stacking, crane break down, wrong labeling on coils, etc. This research work can be applied for the vehicle dispatch process of various other products inside the plant. Further studies could apply similar simulation models to analyze logistics systems of several other industries. The scope of this approach can be considered for other process types like production, transport and inventory management.

Acknowledgements The authors express their sincere thanks to Sanjeev Singh (Plant supply chain head) and Nandakishore Modi 
(Plant dispatch head) for their support in the achievement of this work.

\section{References}

1. Potter A, Yang B, Lalwani C (2007) A simulation study of despatch bay performance in the steel processing industry. Eur $\mathrm{J}$ Oper Res 179(2):567-578

2. Womack J, Jones D (1996) Lean thinking. Simon and Schuster, New York

3. Manson SJ, Ribera PM, Farris JA et al (2003) Integrating the warehousing and transportation functions of the supply chain. Transp Res E 39(2):141-159

4. Potter A, Lalwani C (2007) Developing a methodology to analyse despatch bay performance. Int J Prod Econ 106(1):82-91

5. Juntunen J, Juga J (2009) Controlling the bullwhip with transport capacity constraints. Int J Serv Stand 5(2):160-171

6. Zhao QH, Chen S, Leung SCH et al (2010) Integration of inventory and transportation decisions in a logistics system. Transp Res E 46(6):913-925

7. Yeh IC (1995) Construction-site layout using annealed neural network. J Comput Civil Eng 9(3):201-208

8. Malakooti B, Tsurushima A (1989) Expert system using priorities for solving multiple-criteria facility layout problems. Int J Prod Res 27(5):793-808
9. Rother M, Shook J (2003) Learning to see: value stream mapping to create value and eliminate muda, version 1.3. Lean Enterprise Institute, Brookline

10. Hines P, Rich N (1997) The seven value stream mapping tools. Int J Oper Prod Manage 17(1):46-64

11. Chang Y, Makatsoris H (2001) Supply chain modeling using simulation. Int J Simul 2(1):24-30

12. Kleijnen JPC (2003) Supply chain simulation: a survey. CentER Discussion, Tilburg University

13. Disney SM, Naim MM, Potter A (2004) Assessing the impact of e-business on supply chain dynamics. Int J Prod Econ 89(2): $109-118$

14. Sterman JD (2000) Business dynamics: systems thinking and modelling for a complex world. McGraw-Hill, Boston

15. Spedding TA, Sun GQ (1999) Application of discrete event simulation to the activity based costing of manufacturing systems. Int J Prod Econ 58(3):289-301

16. Persson F, Olhager J (2002) Performance simulation of supply chain design. Int J Prod Econ 77(3):231-245

17. Kelton WD, Sadowski RP, Sturrock DT (2004) Simulation with arena. McGraw-Hill, New York

18. Oral M, Kettani O (1993) The facets of the modeling and validation process in operations research. Eur J Oper Res 66(2): 216-234 